\author{
OLGA LISYOVÁ
}

Facultad de Filosofía, Universidad de Prešov

\title{
EL PROBLEMA DE DEFINICIÓN DE LA PERÍFRASIS VERBAL EN ESPAÑOL (DUDAS Y CONTRADICCIONES)
}

\begin{abstract}
Lisyová Olga, El problema de definición de la perifrasis verbal en español (dudas y contradicciones) [On the definition of periphrastic verbal constructions in Spanish language (doubts and contradictions)]. Studia Romanica Posnanicnsia, Adam Mickiewicz University Press, Poznań, vol. XXXl: 2004, pp. 329-342. ISBN 83-232-1353-4, ISSN 0137-2475.
\end{abstract}

The theme of this contribution originated from contradictory understanding of the conception of periphrastic verbal constructions by different linguists. In spite of the fact that most of the grammars consider as being periphrastic the constructions consisting of a rigid form of the full-meaning verb (infinitivo, gerundio, participio pasado), they diverge in the delinition of the auxiliary verb. We discuss the substantiation to name various verbal constructions as pcriphrastic. We come from the basic definition of the periphrasis as a descriptive expression, the semantic significance of which is formed by a synthesis of its constituents, but not by the constituents themselves.

\section{INTRODUCCIÓN}

El uso frecuente de la perífrasis verbal en la lengua es popular a causa de su forma que lleva rasgos de dicha figura estilística. La mencionada construcción aporta considerablemente el enriquecimiento del discurso y ofrece la posibilidad de expresarse de una manera más viva y variada. No obstante, la definición de la perífrasis verbal en las gramáticas muchas veces es contradictoria e imprecisa. La significación propia de la palabra "perífrasis" según el diccionario de Real Academia Española equivale a circunlocución - "figura que consiste en expresar por medio de un rodeo de palabras algo que hubiera podido decirse con menos o una sola, pero no tan bella, enérgica o hábilmente". Esta definición de perífrasis como una figura estilística nos puede servir de apoyo y ayudará a precisar la definición de la perífrasis verbal que, a pesar de no ser puramente una figura estilística, conserva este principio de la circunlocución, o sea, lleva la capacidad de expresar una acción no con un solo verbo, sino con ayuda de dos formas verbales (una personal y otra no personal). 
La mayoría de los gramáticos españoles como Gilli Gaya en el Curso superior de sintaxis española, Emilio Alarco Llorach en Gramática de la lengua española, igualmente que en las obras colectivas, Esbozo de una gramática nueva de la lengua española, coincide en la opinión común de que la perífrasis verbal no presenta una mera suma de los significados de sus componentes, sino que adquiere un sentido nuevo que muchas veces tiene relaciones sinonímicas con los verbos (trae revuelto todo el pueblo - revuelve todo el pueblo, se puso a reír - se rió) u otras construcciones (me pongo a estudiar - empiezo a estudiar - voy a estudiar, llevo trabajando tres horas - permanezco trabajando tres horas - estoy trabajando tres horas).

Consideramos adecuado citar a Javier Garcia González que dice en su obra Perifrasis verbales: "El significado total de la perífrasis es distinto del que pueda resultar de la suma de los significados de sus componentes" (pág.15). Pues, el que lleva el cargo gramatical de la construcción y marca la persona y el número es el verbo auxiliar; las formas no personales llevan el cargo semántico añadiendo los matices incoativo (construcciones con infinitivo), durativo (construcciones con gerundio), o atribuyen el carácter perfectivo a las construcciones con participio. Emilio M. Martínez Amador (pág. 155) llama toda especie de las construcciones verbales "conjugaciones perifrásticas", incluyendo a este grupo las formas compuestas de tiempo y la forma de la voz pasiva. Sería el motivo, por el cual este autor designa cualquier forma compuesta verbal, sea una construcción verbal o la forma compuesta de tiempo como "conjugación perífrastica" por razones meramente formales (verbo en la forma personal y otra en no personal), o se dirigiría por el principio que "la conjugación es una serie ordenada de las distintas formas del mismo verbo o comunes a un grupo de verbos de igual flexión, con las cuales se denotan sus diferentes modos, tiempos, números y personas" (RAE, 82); de todos modos esta definición del autor provoca dudas y aspira a compararla con otros gramáticos que se ocupan del problema de las perífrasis verbales.

Hablando de la perífrasis verbal es necesario resolver una serie de problemas. La primera dificultad la presenta el problema de la definición de perífrasis, tomando en cuenta presenta dicha construcción verbal la creación de un significado nuevo o es una suma de los componentes, en nuestro caso del verbo en la forma personal y otra derivada del verbo. Aquí las opiniones de los lingüistas se diferencian. Por ejemplo, M. Seco en su Gramática esencial de español dice que: “(...) una perífrasis no crea nada, modifica tan solo el significado de uno de los componentes, que es la forma no personal (en lo cual se asemeja a las palabras con afijos apreciativos)", a continuación presenta ejemplos, comparando las frases - "tengo que salir, o tengo que esperar" - dice que "los dos significados de salir y esperar se quedan «intactos» y lo único que ocurre es que el verbo en forma personal «no enuncia el hecho, sino la necesidad u obligación»" (pág. 336).

Esta sentencia del autor también provoca ciertas dudas, porque nos parece bastante atrevido afirmar que "la perífrasis verbal no expresa nada, modifica tan 
solo el significado de la parte no personal del verbo", con que rechaza completamente el papel de los verbos semiauxiliares o semisignificativos que influyen hasta cierto punto al significado final de la frase (este coche me viene costar muy caro; ando pensando en ella; ya lo tengo hecho; nos vemos obligados a...). Según nuestra opinión la carga significativa del verbo en forma personal influye evidentemente al significado total de la frase (Pienso en ella todo el día, ando pensando en ella todo el día, estoy pensando en ella todo el día, tengo que pensar en ella todo el día, llevo mucho tiempo pensando en ella) - lo mismo que las formas no personales del verbo además de su valor léxico introducen en la frase también el significado complementario del aspecto (ponerse a escribir, echarse a llorar, romper a reír - sentido aspectual de la acción incoativa; estar estudiando, llevar trabajando - valor durativo, progresivo; ya lo tengo hecho, dar por comprendido - valor aspectual de la acción perfectiva, terminativa; de tiempo acabo de leer este libro, voy a ocuparme de este asunto, de modalidad - debe de ser las dos - sentido de probabilidad, tengo que irme - el de obligación) etc.

\section{DEFINICIÓN DEL TÉRMINO DE PERÍFRASIS}

1. Analicemos las opiniones relacionadas a este problema de los lingüistas españoles y extranjeros.

Parece unánime la idea principal de la perífrasis verbal referida a su forma, o sea, las construcciones verbales que incluyen el verbo en forma personal (el verbo auxiliar) y la no personal del verbo - infinitivo, participio, gerundio (forma auxiliada), pero nos enfrentamos con la contradicción a la hora de definir el concepto principal de cada conjunto.

Según E.A. Llorach: "El nucleo oracional puede consistir en una combinación de unidades que funciona en conjunto como un solo verbo. Se llaman perífrasis verbales. De los cuales un componente es el verbo en forma personal, segundo que presenta una forma derivada verbal, infinitivo, gerundio, participio" (pág. 259).

Javier Garcia González se dedica especialmente al problema de la definición de perífrasis, su definición de la forma de perífrasis coincide con los demás, dice: "En cuanto a la forma, entenderemos como perífrasis verbales únicamente aquellas construcciones que estén constituidas por un verbo en forma personal (conjugado) unido directa $o$ indirectamente (con o sin preposiciones o mediante que), y un verbo en forma no personal (infinitivo, gerundio, participio)" (pág. 14).

Emilio M. Amador respecto a la forma de las construcciones verbales, que él nombra "conjugaciones perífrasticas", dice: "Todas ellas tienen en común la formación mediante un verbo auxiliar con un participio, un gerundio y principalmente un infinitivo. Entre el auxiliar y este último se interpone la conjunción que o una preposición" (pág. 155). 
El primer desacuerdo viene con la tarea de determinar la noción del verbo auxiliar. Este problema es muy importante porque al encontrar la formulación más o menos exacta y correcta de éste podríamos intentar delimitar el término gramatical de la perífrasis verbal, eliminando las construcciones verbales que no son perifrásticas. Según el Esbozo de la nueva gramática... presentamos la siguiente característica del verbo auxiliar: "Decimos que un verbo desempeña la función de auxiliar cuando, al encabezar una perífrasis, pierde total o parcialmente su significado propio" (pág. 444). Este índice del auxiliar lo consideramos por el más importante a la hora de determinar correctamente la perífrasis verbal. Guiándonos por esta idea, podemos analizar algunas perífrasis, comentando la pérdida completa o parcial de la significación inicial del verbo auxiliar.

El cadáver del niño estaba allí y nadie llegaría a saber la causa de su muerte (J. Goytisolo).

En aquel momento el timbre volvió a sonar y todos nos levantamos (J. Goytisolo).

Batiste tenía que labrar una parte del terreno que ain conservaba inculto (V. Blasco lbañez).

Gregorio se dejó caer en su silla igual que un paquete (J. Goytisolo).

Arriba están presentados algunos ejemplos de las perífrasis verbales del repertorio rico de este fenómeno. Los verbos que se hallan en forma personal son: llegar (llegaría a saber), volver (volvió a sonar), tener (tenía que labrar), dejar (se dejó caer). Todos los verbos presentados han perdido su significado primitivo de la manera diferente.

En la frase nadie llegaría a saber - el verbo llegar ya no posee su significación principal de movimiento, aproximación, sino además de funcionar como auxiliar de Ia frase añade a ésta el matiz perfectivo de la acción. Esta acepción perfectiva a menudo adquiere también el verbo "acabar" que formando la perífrasis verbal acabar de + inf. (Acabamos de llegar ahora mismo), pierde su significado originario "poner o dar fin a una cosa" y da a la frase el valor del pasado inmediato.

En la construcción volvió a sonar - el verbo volver parcialmente perdió el sentido de dar vuelta a una cosa, e indica que la acción, expresada por el infinitivo, se repite (el matíz de reitiración).

En el caso en que el verbo aún conserve su sentido de movimiento, no hay perífrasis. Ej.: Volvemos felices al pueblo a comer y descansar un poco.

El verbo tener en la frase tenía que hablar completamente se vacía del sentido directo de este verbo, que es el sentido posesivo y adquiere un sentido nuevo que es obligación.

El significado del verbo dejar en la frase se dejó caer en su silla - el verbo en vez de su sentido principal de soltar una cosa, permitir algo (ej.: Por fin me dejó hablar), agrega a toda la expresión el sentido de una acción acabada, perfectiva.

Es interesante seguir la alteración del sentido directo del verbo dejar en la frase dejar de + inf., en la cual expresa interrupción o fin de una acción. Referido a este 
caso se puede asegurar que la frase tiene el sentido terminativo porque expresa el fin de la acción y equivale a las construcciones como terminar de + inf., cesar de + inf. Ej.: Lejos de dejar de ir a casa de Pepita, voy más temprano todas las noches (J. Valera). El valor perfectivo de la frase verbal con dicho verbo se refuerza si la segunda parte de la frase es representada por el participio pasado, lo mismo se refiere a los verbos quedar y traer. Emilio M. Amador presenta los siguientes ejemplos con las formas en cuestión: "dejó empezadas las novelas", "mi amigo quedó desalentado", "trae revuelto a todo el pueblo" (pág. 157).

Ahora bien, nos toca a nosotros la tarea de intentar resolver si todas las combinaciones de verbos en forma personal y las formas derivadas verbales y infinitivo presentan una perífrasis verbal. En este punto, a pesar de la definición más o menos unánime, se desvían las opiniones de incluir o no tal o cual construcción entre perifrásticas. La mencionada discordancia se toca principalmente a frases como comenzar $a+$ inf., terminar de + inf., deber + inf., soler + inf., continuar + gerundio, seguir + gerundio etc., en las cuales el valor de la acción durativa, obligativa o terminativa de la frase debe al significado propio, original del verbo en forma personal. Gili Gaya opina que: "No hay que perder de vista que el carácter de las frases así logradas son como una suma en que los sumados están visibles por separado, y no un producto nuevo en que el primer verbo se ha vaciado de su significado total o parcialmente" (pág. 109). Resaltando este principio fundamental del verbo auxiliar advierte que: "(...) de lo contrario podríamos aumentar hasta un número incalculable las expresiones que estamos estudiando" (pág. 109). Efectivamente si comparamos la carga semántica, por ejemplo, de los verbos en las frases siguientes:

tengo que decirte la noticia debo decirte la noticia: este año me pongo a estudiar este año comienzo a estudiar: ya llevamos charlando mucho tiempo permanecemos charlando mucho tiempo no llegué a comprender el problema, no alcancé a comprender tu problema

El análisis de los ejemplos presentados arriba, nos muestra que las frases marcadas pierden total o parcialmente su significado primitivo y en combinación con la forma auxiliada forman un significado completamente nuevo de la acción obligativa, incoativa, durativa, terminativa. Al contrario los verbos de otras tres frases expresan el mismo valor aspectual o modal gracias a su significado inicial. Conformándonos con la misma idea expresada en El curso superior... de Gilli Gaya podemos resumir que estas frases son un producto lexicológico y no gramatical, por consiguiente no podemos definirlas como perífrasis.

A veces, en algunas gramáticas los autores, pese a presentar la definición básica del verbo auxiliar, presentan los ejemplos de las frases en las cuales el verbo conserva plenamente su valor esencial. Por ejemplo E.A. Llorach en La gramática de la lengua española (pág. 259) dice que: "(...) existen combinaciones de una forma verbal y un derivado que no han de interpretarse como perífrasis; no actúan 
como segmentos unitarios nucleares, sino como reunión de núcleo y adyacente" - y continúa "la frontera entre ambas posibilidades se cree impuesta por particularidades semánticas: si el verbo auxiliar conserva su habitual referencia de sentido, no hay perífrasis". Hasta aquí estamos completamente conformes y por eso nos sorprende que este autor por una parte considera las frases con querer, poder (pág. 260) como no perifrásticas, pero por otra parte el mismo autor presenta los ejemplos con los verbos poder, soler, deber (puedes comprar estos libros, sueles comprar estos libros, debes comprar estos libros (pág. 261) como "auténticas perífrasis", lo que nos hace pensar que el autor no es consecuente con la tesis que ha postulado, porque las determina como perífrasis verbales, a pesar de que conservan su valor inicial.

Otra contrariedad de la definición de perífrasis verbal vemos en el manual Español 2000 de Jesús Sánchez Lobato y Nieves Garcia Fernández (pág. 130-135) en el que la definición de la perífrasis verbal es la siguiente: "Se llama perífrasis verbal a la concurrencia de dos formas verbales, destinadas a expresar un contenido informativo distinto de la mera suma de los contenidos informativos de cada una de las formas verbales. Los dos elementos constituyentes de la perífrasis no tienen la misma función ni la misma forma: Uno de ellos, invariable en cuanto a la flexión verbal, aporta el contenido léxico: el significado. El otro, variable, aporta los morfemas de persona, número, tiempo, modo, y es llamado auxiliar. En esta función pierde su significado propio". Esta definición no se distingue de las citadas en las líneas anteriores pero nos extrañan los ejemplos de estos autores en el pártafo que viene a continuación, donde presentan en el papel de perífrasis las frases como continuar + gerundio, seguir + gerundio, empezar a + inf., terminar + gerundio, comenzar a + inf., alcanzar a + inf., deber + inf. (pág. 132-133) con que se nota evidente contradicción.

Como ya hemos mencionado, Emilio M. Amador tampoco hace diferencia entre los verbos que han perdido su significado propio y los que lo han conservado por completo en las frases verbales, todos los verbos en la forma personal los denomina auxiliares. Nos parece inadecuado abarcar en el mismo grupo las frases verbales con el verbo con un cierto o absoluto grado del aislamiento gramatical como: estar + gerundio (estoy leyendo), llevar + participio (llevo escritas dos páginas), tener + participio (tenía perdidas las esperanzas), haber de + inf. (he de hacerlo), echarse a + inf. (se echó a correr), etc., frente a las frases con los verbos: desear, intencionar, pensar, creer, temer, esperar, necesitar, sentir, soler, seguir, etc. que intervienen con su valor semántico inicial. Igualmente Ramón Sarmiento introduce en el mismo grupo tanto las locuciones del tipo deber de + inf., como las con el verbo deber + inf; ; poder + inf. (pág. 189).

La confusión de los verbos significativos y auxiliares la notamos en las obras de algunos hispanistas rusos. Por ejemplo E.V. Litvinenko en la Gramática de la lengua española (pág. 115) determina las contrucciones perifrásticas, especialmente con infinitivo, de la manera siguiente: "Algunos de dichos verbos empleados 
con el infinitivo pierden casi por completo su propio significado léxico, se hacen semiauxiliares y toda la construcción verbo en forma personal + infinitivo adquiere un significado especial, modal, temporal o de aspecto, impropio de cada uno de sus elementos usados separadamente". Entonces provoca el conflicto la definición del fenómeno con los ejemplos sacados del mismo párrafo que se presentan como perifrásticas: comenzar $a+$ inf., empezar $a+$ inf., principiar $a+$ inf., iniciar $a+$ inf., terminar de + inf., cesar de + inf. - con el significado temporal; saber de + inf. de significado modal, en las cuales el verbo sigue conservando plenamente su sentido propio.

Otro grupo de autores O.K. Vasilieva-Švede, G.V. Stepanov en la Gramática teórica de la lengua española (pág. 245) clasifican las frases verbales de manera distinta: las gramaticalizadas y léxico-sintácticas. Las frases gramaticalizadas, según estos autores, son las que pierden por completo su significado independiente y adquieren una cualidad nueva de tiempo, aspecto o de modo; en la oración desempeñan el papel del predicado simple. Este grupo incluye frases tales como acabar de + inf., ir a + inf., deber de + inf., echarse $a+$ inf., ponerse $a+$ inf., volver $a+$ inf., haber de + inf., tener que + inf.

De las construcciones léxico-sintácticas sirven tales como: soler + inf., acostumbrar(se) + inf., dignarse + inf., incluso con los verbos atreverse, limitarse, donde los verbos auxiliares han perdido del modo distinto su principal valor léxico. En la oración estas construcciones sirven de predicado compuesto verbal a diferencia de las construcciones gramaticalizadas. Los autores opinan que los verbos poder, querer, deber, saber (en el sentido directo de la palabra) forman las construcciones descriptivas modales. Con el participio y gerundio los mencionados lingüistas dividen las frases verbales por el mismo principio: en gramaticalizadas, como haber + participio, ser + participio, tener + participio, estar + participio, estar + gerundio; y léxico - sintácticas con los verbos ir, andar, seguir, permanecer, quedar + participio, ir + gerundio, seguir + gerundio, continuar + gerundio, andar + gerundio, venir + gerundio, quedarse + gerundio, permanecer + gerundio, llevar + gerundio, a pesar de que algunas de éstas cumplen las condiciones de ser perifrásticas, porque los verbos en forma personal pierden o modifican parcilamente su significado original. Éstos merecen ser nombrados semiauxiliares o semisignificativos. Así, por ejemplo, en las frases: "lo voy observando mucho tiempo; anda haciendo rumores; esto me viene a costar mucho dinero; no llega a comprender lo sucedido", el valor de movimiento se persiente todavía en la frase, pero sólo para dar a la frase un matíz especial del dinamismo, desarrollo o resultado de la acción. Por este mismo principio divide las construcciones verbales el hispanista eslovaco L. Trup en Gramatika španielskeho jazyka (pág. 232-233). Analizando este método de clasificación de las frases verbales, se puede resumir que los autores sin denominar ninguno de los grupos con el término perífrasis, por lo menos, ponen una barrera visible entre el grupo con el verbo auxiliar completamente vaciado de su significado propio (construcciones 
gramaticalizadas) y el otro con el verbo semivaciado o en el que conserva su sentido propio (construcciones léxico-sintácticas o descriptivas).

El plantear el problema del grado de la gramaticalización del verbo en las frases verbales nos parece importante, porque la comprensión de éste ayuda a resolver la duda de incluir o no entre perífrasis las construcciones completamente vaciadas o gramaticalizadas (formas compuestas de tiempos verbales, voz pasiva) igual que las frases con los verbos en la forma personal, los que conservan en absoluto su significado propio (empezar a + inf., terminar de + inf., soler + inf., seguir, continuar + gerundio, etc.), los verbos modales.

\section{VERBOS MODALES}

Esta contrariedad nos hace pasar a otro grupo de las construcciones verbales que conservan plenamente su valor inicial, "sirven para describir la actitud del hablante respecto de la acción expresada por el infinitivo" - A. Llorach (pág. 260) y consideradas por algunos autores perífrasis verbales. Son frases que según su forma (verbo en forma personal + inf.) se parecen a las perífrasis, pero no cumplen la condición principal de éstas: el verbo auxiliar debe parcial o completamente perder su significado propio y toda la frase adquiere el sentido distinto al de cada componente separado. Son frases con los verbos modales (deber + inf., querer + inf., poder + inf., etc.), que deben su valor semántico y su modalidad al significado directo de los verbos, conque no los podemos considerar por auxiliares, ni toda la construcción verbal por perífrasis. Al contrario, las frases que expresan el valor modal a base de la síntesis de sus componentes, en las cuales el verbo se vacía de su sentido primitivo total o parcialmente sí que las definimos como tales, por ej.: deber de + inf:; (probabilidad) - debe de ser lunes; haber de, haber que; tener que + inf.: he de decirselo, hay que consultar este problema; tengo que reservar el pasajeque expresan la obligación.

Ahora bien, para resolver este problema, estudiaremos las opiniones de los lingüistas ya presentados antes. Hay que mencionar que, a pesar de la definición consólidada o similar, la referencia hacia los verbos modales muchas veces se contrapone y lleva consigo mucha confusión. J.G. González dice (pág. 18): "Los verbos modales (poder, querer, deber, soler) aparecen frecuentemente acompañados de un infinitivo (soler en todos los casos); en estos contextos sirven para describir la actitud del hablante respecto de la acción expresada por el infinitivo. Tienen, así, muchos puntos en común con los verbos auxiliares. (...) Sin embargo, nosotros sólo consideramos como perífrasis aquellas construcciones en las que el verbo en forma personal se encuentra gramaticalizado, al menos parcialmente". Apoyándonos en esta afirmación no podemos conformarnos con los ejemplos de este autor, donde presenta como perífrasis frases verbales tales como: hartarse de + inf., alcanzar a + inf., conseguir, lograr a + inf. Gilli Gaya dice respecto a este problema: "Hay un 
grupo de verbos que algunos incluyen entre los que estamos estudiando. Tales son hacer (hacer venir - factitivo), dejar, permitir, mandar, poder, deber, querer y algunos más. Si nos fijamos, sin embargo, en las expresiones que forman cuando van seguidas de infinitivo, notaremos en seguida que sólo excepcionalmente tienen función de auxiliares" (pág. 111). En el Esbozo de la nueva gramática... (pág. 450) se dedica un capítulo especial referido a la cuestión de los verbos modales y se considera que: "Las perífrasis que hemos enumerado hasta aquí denotan modificaciones semánticas de la acción verbal expresadas con medios gramaticales. La gramaticalización del verbo auxiliar - decíamos - consiste en la pérdida total o parcial de su significado (...) Los verbos deber, querer, saber y poder denotan el modus explícito de las oraciones citadas (deben estudiar, quieren trabajar, pueden trabajar) como ejemplos, el infinitivo es el dictum, el contenido esencial de la representación. Por eso se llaman verbos modales. (...) La lista de éstos puede ser muy larga. Entrarian en ella todos los que significan comportamiento, intención, deseo, voluntad: intentar, mandar, desear, prometer, esperar, proponerse, procurar, pretender, pensar, etc."

M. Seco en la Gramática esencial... (pág. 337) dice: "Suelen darse como perífrasis también las construcciones formadas por deber, poder, querer, saber (llamados verbos modales) + inf. Se trata solamente de verbos que tienen como complemento directo habitual el infinitivo". Entonces no las considera perífrasis, basándose en la idea de que el infinitivo en estas frases modales desempeña el papel de complemento directo.

Haciendo un resumen respecto a incorporar o no las frases modales entre las perífrasis opinamos que a base del análisis de dichas frases y la deducción lógica de lo escrito anteriormente, no podemos considerar los verbos modales por auxiliares porque no han sufrido ningún tipo de gramaticalización, así que toda la frase no adquiere un valor nuevo y su modalidad es dada solamente al significado directo del verbo en forma personal.

\section{FORMAS COMPUESTAS DE TIEMPO, VOZ PASIVA}

Tomando en cuenta las formas compuestas de los tiempos verbales se podría incorporar éstas en el grupo de las perífrasis verbales según su estructura: el verbo en forma personal + participio.

Por la mañana he visto a María.

Cuando desperté ya había oscurecido.

Mi amigo me dijo que el lunes que viene para las tres él ya habría terminado este trabajo.

Es evidente que el verbo haber en estas frases perdió por completo su significado inicial antiguo de "poseer una cosa, ser necesario o conveniente" y toda 
la construcción verbal no lleva ninguna carga semántica, al revés nos muestra sólo una categoría puramente gramatical del verbo: el tiempo. El verbo haber no lleva ninguna información desde el punto de vista de su significado, y por consiguiente toda la frase provoca el conflicto con la denominación de perífrasis que delimita las construcciones perífrasticas de otras formas verbales compuestas por su capacidad de crear un concepto nuevo.

En Perífrasis verbal J.G. González dice: "En el caso del verbo haber + participio esta construcción forma parte ya de la conjugación del verbo y presenta unas especiales características que la diferencia de las perífrasis verbales". Entre estas características además de la gramaticalización completa del verbo y pérdida total del valor semántico de toda la frase, el autor destaca lo imposible del uso independiente del verbo haber. "El verbo haber, al estar muy gramaticalizado, necesita, en casi todos los contextos al participio: he perdido las gafas. Sólo en construcciones impersonales no tiene que aparecer el participio. Los verbos que son auxiliares en las perífrasis, al contrario, pueden aparecer de forma independiente, sin estar gramaticalizados en todos los contextos" (pág. 19). Es decir, las formas de los tiempos compuestos y la pasiva exclusivamente por su forma pueden ser incorporadas a las perífrasis, pero son gramaticalizadas hasta el punto de que ya expresan sólo forma gramatical, vacía semánticamente. Se recordará nuevamente la opinión de Gilli Gaya respecto a la construcción haber + participio en Sintaxis de..., (pág. 116), donde dice: "(...) la idea de la anterioridad temporal que lleva consigo, la perfección de la acción convierte tales perífrasis predominantemente en «tiempos» del verbo, y ésta es su principal significación en la lengua moderna". Analizando la característica de este lingüista podemos decir que, a pesar de nombrar esta construcción como perifrástica, admite su naturaleza puramente gramatical, lo que resulta incompatible con la interpretación propia de la perífrasis verbal. Para completar la idea de la construcción haber + participio seguimos consultando otras fuentes, por ej. Esbozo de una gramática... (3.12.6.), citamos: "El participio precedido de verbo auxiliar forma perífrasis de significación perfectiva. Sabido es que el verbo haber seguido de participio forma los «tiempos compuestos» de la conjugación. Estas perífrasis significaron en su origen la acción perfecta o acabada en el tiempo en que se halla el auxiliar haber, es decir, la acción acabada en el presente". Por cierto, lo escrito en este párrafo coincide por completo con la misma idea presentada por Gilli Gaya, con la cual no podemos estar de acuerdo por razón de la denominación fundamental de perífrasis. M. Seco en la Gramática esencial... (pág. 33) menciona que: "Pero las perífrasis verbales más importantes son las construidas por haber + participio. Las primeras son las que conocemos en la conjugación como "tiempos compuestos» y tienen la particularidad de que en ellas el participio es invariable: he cantado, hemos cantado. Las segundas forman la "construcción pasiva» fue vencido, serian aceptadas. A estas dos perífrasis podemos añadir soler + inf. (Solíamos coincidir en la parada del autobús), en que «soler en forma personal es un verbo auxiliar». Referido a lo opinado por este autor, 
volvemos a nuestra réplica expresada anteriormente (el verbo soler no se puede considerar por auxiliar por su sentido directo en la frase, las construcciones de los tiempos pasados no crean las perífrasis por la pérdida total de cualquier significado semántico).

La voz pasiva construida mediante los verbos ser, estar + participio también sirve del tema de discusiones. Ya el término mismo de la voz pasiva provoca discrepancias entre gramáticos. Gramática moderna según Emilio M. Amador no admite la forma de la voz pasiva tradicional, pues ni siquiera tiene la forma estereotipada del participio como en los tiempos compuestos de la activa (se refiere a las alternancias genéricas del participio de la voz pasiva). Siguiendo este tema dice: "Gramática tradicional considera que los verbos conjugados en la supuesta voz pasiva no hacen sino expresar una relación atributiva, en la que el participio se convierte en un predicado nominal. Decimas: ella es amada, lo mismo que decimos: ella es buena" (pág. 685). R. Lenz cosidera que la voz pasiva "formada con auxiliar ser no tiene ni mayor ni menor derecho de existencia que las demás voces (la obligativa, la durativa, la progresiva, etc.)". Otros gramáticos atribuyen la pasiva a las demás frases verbales; no obstante, la mayoría de los autores, basándose en la estructura de la pasiva, la definen como perifrástica, tomando en cuenta su estructura analítica frente a las formas sintéticas del latín.

En total, es evidente que el verbo ser si lo consideramos el verbo auxiliar de una construcción verbal o el verbo copulativo del predicado nominal sufrió la gramaticalización total y no influye de ninguna manera al valor semántico final de la frase, así que resulta muy dudosa su integración a las perífrasis verbales.

\section{CONTEXTO}

Según el análisis de algunas frases se puede ver que unos verbos y por consiguiente, las frases pueden ser consideradas perífrasis según el contexto. Por ejemplo, la construcción verbal acabar de + inf. es perífrasis en el caso de la pérdida del verbo acabar de su sentido propio de "poner o dar fin a una cosa"; el verbo se gramaticalizó tanto que la frase adquirió el sentido temporal del pasado inmediato. Ej.: La desenvuelta Antoñona acaba de entrar a verme (J. Valera). Pero en algunos casos, pese a conservar la misma forma del verbo personal y infinitivo, toda la frase debido al significado terminativo del verbo lleva esta significación, así que no podemos definirla como perífrasis. Ej.: Acabo de leer este libro y me voy a preparar la cena. Ej.: "Cuando don Cristobal acabó de arreglar su nueva casa cogió el portante y se marchó al café" (J. Cela).

Otro ejemplo del cambio significativo de la frase según el contexto lo mostraremos en el ejemplo del verbo ir en las construcciones verbales ir + inf.: Voy a casa a comer, voy a estudiar toda la tarde. En la primera oración el verbo ir conserva su significado de movimiento y por eso la frase no puede ser considerada 
por perifrástica. El segundo ejemplo lo determinamos como perífrasis a base de la gramaticalización casi completa del verbo auxiliar ir y el significado de ésta de futuro inmediato. Otros pares de oraciones confirman esta afirmación:

Ando (camino) contento por las montañas. Ando preocupado todos los días.

Vengo a decir que Juanita ha llegado ya. Lo sucedido viene a provocar mucho escándalo.

No puedo hacerlo. María puede estar enferma (María probablemente está enferma).

Debes cumplir esta tarea a tiempo. Nuestro padre debe (de) estar en el garaje (esta frase puede tener dos sentidos - el primero directo de obligación, el segundo una forma coloquial de la perífrasis deber de + inf.).

Es evidente que en muchos casos el significado de la frase perifrástica se debe a la significación figurada del verbo respectivo, es ante todo la particularidad de los verbos semiauxiliares, lo que se percibe en mayor o menor grado. En cuanto a esta afirmación J.G. González dice que: "Tampoco incluimos entre las perífrasis verbales las construcciones en las cuales el verbo en forma personal varía su significado al tomar una acepción figurada" - presenta el ejemplo: "Luis se lanzó a recoger noticias" (pág. 19). Opinamos que es muy difícil establecer el límite fijo entre el grado de la gramaticalización del auxiliar y el nivel de la figuración basada en la asociación del verbo con su sentido inicial:

- puede estar enferma (sentido directo - 1. tener facilidad, tiempo o lugar de hacer una cosa, 2. fig. ser contingente o posible que suceda una cosa);

- ponerse a correr (1. sentido directo - colocar en un sitio o lugar una persona o cosa, o disponerla en el lugar o grado que debe tener, 2. fig. dedicar a uno a un empleo o oficio);

- echarse a llorar (1. sentido directo de la palabra - hacer que una cosa vaya a parar a alguna parte, dándole impulso, 2. fig. arrojarse a una acción - se asocia a lanzarse a recoger noticias);

- pasar (1. llevar o transmitir de un lugar a otro 2. mudar, trasladar a uno de un lugar o de una clase a otro). Pasar a + inf. - sentido incoativo - este verbo conserva casi siempre su significado directo o figurado: Después de la comida pasamos a jugar a ajedrez. En este mismo paso a contestar a su carta (no se basa el significado nuevo de la citada perífrasis en el significado figurado del verbo "pasar de una acción a otra?"). "Con la destrucción de Cartago los romanos pasaban a ser dueños del Mediterráneo" (Llorach, pág. 109).

En cuanto a la gramaticalización completa del verbo auxiliar, no cabe duda que aquí el verbo pierde totalmente su significado y toda la frase adquiere un sentido distinto al original del verbo; pero referido a los verbos semiauxiliares o con la pérdida parcial del significado propio se puede hablar del sentido figurado en base a una asociación con el sentido directo, inicial del verbo que sin nombrar directamente la acción debido su significado se percibe e influye al significado total de la frase. 


\section{CONCLUSIONES}

La perífrasis verbal es un medio muy productivo en el enriquecimiento de la lengua. Muchas veces forma parte de la cadena sinonímica del léxico. Es sabido que la lengua que posee de varios métodos de expresar la misma o parecida noción se reconoce como rica (igualmente podemos decir: me pongo a estudiar - empiezo a estudiar, voy a estudiar, etc.). Originariamente la perífrasis era conocida como uno de los medios estilísticos que sirven para determinar los conceptos en forma de giro sinonímico en relación con la palabra anteriormente existente. Con ella se designa un objeto o persona por medio de un rodeo para dar mayor energía o elegancia al pensamiento, es decir, expresa por medio de circunloquios to que podría decirse con menos palabras. El fenómeno léxico - gramatical de la perífrasis verbal surgió tomando el mismo principio de expresar una noción mediante un giro, en nuestro caso, de varios grados de gramaticalización.

Aquí presentamos las condiciones más importantes de las perífrasis verbales.

La primera es creación de un nuevo significado y no la suma de los componentes que las forman (el verbo auxiliar + participio, gerundio, infinitivo). Opinamos que las frases como echar(se) $a+$ inf., ponerse $a+$ inf., tener que + inf., tener + participio, deber de + inf., haber de + inf., estar + gerundio, etc. cumplen esta primera condición.

Para solucionar la cuestión de si vale o no tal o cual construcción verbal como perifrasis hay que prestar atención al verbo auxiliar, porque el grado de su gramaticalización es el que determina la perífrasis. Consideramos auxiliares aquellos verbos que han vaciado su significado propio de grado diferente. Eso se refiere a los verbos de movimiento andar, ir, venir, llegar que generalmente son semiauxiliares (pero hay que eliminar los casos, en que conservan su sentido propio en el contexto), el verbo tener (tener que + inf., tener + participio), estar (estar + gerundio, estar + participio), poner (ponerse $a+$ inf.), etc. Excluimos de este grupo las construcciones como empezar a + inf., seguir + gerundio, alcanzar + inf., construcciones modales que se asemejan por el papel que desempeña en ellas el verbo. No podemos calificarlos auxiliares porque conservan plenamente su significación y como resultado, toda la frase tiene el valor incoativo, modal, aspectual, etc. sólo debido a su naturaleza semántica.

Otro extremo que provoca discusiones es la construcción haber + participio y las formas de pasiva. Conocemos la construcción haber + participio como formas de los tiempos compuestos que en la gramática española crean el paradigma de la conjugación de verbo. El verbo haber se gramaticalizó hasta el punto de que se vació de cualquier significación y no lleva ninguna carga semántica. Nosotros no admitimos esta frase verbal como perifrástica por su valor puramente formál.

Por último, queremos mencionar que nuestro estudio no pretiende ser un remedio absoluto para resolver el problema de la perífrasis verbal, surgió con la intención de explicar de la manera más simple y lógica el tema a los estudiantes. 


\section{BIBLIOGRAFÍA}

Alarcos Llorach, E. (1996), Gramática de la lengua española. Madrid: Espasa-Calpe, octava edjción.

Diccionario de la lengua española (1992). Madrid: RAE, vigésima primera edición.

García González, J. (1992), Perifrasis verbal. Madrid: SGEL, primera edición.

Gili Gaya, S. (1990), Curso superior de la sintaxis española. Barcelona: VOX, decímoquinta edición.

Litvinenko, E.V, V jcente, A.S. (1976), Gramática de la lengua española. Kiev: Vyş̌aja škola.

Martínez A mador, E. M. (2000), Mega gramatical y dudas del idioma. Barcelona: Sopena.

Real Academia Española (1996), Esbozo de una nueva gramática de la lengua española. Madrid: Espasa-Calpe, decimosexta edición.

Sánchez Lobato, J., García Fernández, N. (1996), Español 2000. Madrid: SGEL, primera edición.

Sarmiento, R. (1997), Manual de corrección gramatical y del estilo. Madrid: SGEL, primera edición.

Seco, M. (1994), Gramática esencial del español. Madrid: Espasa-Calpe, cuarta edición.

Trup, L. (1997), Gramatika španielciny. Bratislava: Letra.

Vasilieva-Švede, O.K., Stepanov, G.V. (1972), Gramática teórica de la lengua española. Moskva: Vysšaja škola. 